54, 2, pp. 333-344, Warsaw 2016

DOI: $10.15632 /$ jtam-pl.54.2.333

\title{
EVALUATION OF AN ENERGY HARVESTING MR DAMPER-BASED VIBRATION REDUCTION SYSTEM
}

\author{
BOGDAN SAPIŃSKI \\ AGH University of Science and Technology, Department of Process Control, Cracow, Poland \\ e-mail: deep@agh.edu.pl \\ Maciej Rosóe \\ AGH University of Science and Technology, Department of Automatics and Biomedical Engineering, Cracow, Poland \\ e-mail:mr@agh.edu.pl \\ MARCIN WĘGRZYNOWSKI \\ AGH University of Science and Technology, Department of Process Control, Cracow, Poland \\ e-mail: mweg@agh.edu.pl
}

\begin{abstract}
The paper deals with an MR damper-based vibration reduction system with energy harvesting capability. The main part of the system creates an MR damper and a power generator based on an electromagnetic transduction mechanism, which are integrated into a stand-alone device (so called energy harvesting MR damper). The main objective of the work is to evaluate performance of the proposed vibration reduction system employed in a single DOF mechanical structure. The material outlines the design structure and characteristics of the energy harvesting MR damper, presents the vibration reduction system based on this damper and explores experimental testing of the system implemented in a single DOF mechanical structure. To demonstrate that the devised system is feasible, performance figures maps completed by experimental data are shown.
\end{abstract}

Keywords: MR damper, energy harvesting, vibration reduction system, control

\section{Introduction}

Developments of MR damper systems in the last decade have concentrated on energy harvesting capability. Extensive research efforts have been made to develop MR dampers with self-powering and self-sensing capability and to investigate their performance in automobile, railway vehicles and civil engineering applications. Recent years have witnessed a growing number of scientific articles and technical reports on the subject. For example, Cho et al. (2004) investigated an MR damper-electromagnetic generator system whose performance is comparable to that of a conventional MR damper-based system. Besides, Cho et al. (2005) showed that the developed system could be well feasible in civil engineering applications. Hong et al. (2007) proposed an MR damper-electromagnetic generator system and verified its effectiveness in a seismic protection application. Choi et al. (2007) devised such system to generate electricity and ran the experimental testing. Choi and Werely (2009) investigated the feasibility and efficiency of a self-powered MR damper using a spring-mass electromagnetic induction device. Lam et al. (2010) developed and investigated performance of an MR damper with dual-sensing capability to facilitate closed-loop vibration control. Wang et al. (2010) proposed an MR damper-based vibration control system with energy regeneration and showed through of numerical simulations that the system could be feasible when used on an elevated highway bridge. It is worthwhile to mention that some MR damper-electromagnetic generator systems share the self-sensing capability, i.e. it is possible to obtain information about relative velocity across the MR damper based on voltage 
delivered by the generator (Jung et al., 2009, 2010; Wang et al., 2010, 2013). Moreover, Chen and Liao (2012) investigated an MR damper with the power generation feature, integrating energy harvesting, dynamic sensing and MR damping technologies in a single device. Those authors also investigated an MR damper prototype that had the self-powered and self-sensing capabilities. Zhu et al. (2012) designed self-powered and sensor-based MR damper systems for use in large-scale civil structures. Li et al. (2013b) put forward an innovative concept of a mechanical motion rectifier converting bidirectional into unidirectional motion. Attention was also given to regenerative vehicle MR shock absorbers enabling energy recovery from suspension vibrations (Li et al., 2013a). Finally, Snamina and Sapiński (2011) studied the energy balance in a MR damper-based vibration reduction system with the self-powering capability.

This study recalls two former papers by the author, see Sapiński $(2011,2014)$. The first work demonstrated that the developed MR damper-based vibration control system with energy harvesting capability (comprising a commercially available linear MR damper and an electromagnetic power generator prototype) was able to power-supply the MR damper whilst the generator served as a "velocity-sign" sensor. The other study, whose purpose was to integrate the MR damper and the power generator into a single device (also referred to as an energy harvesting linear MR damper) showed that the device was able to recover energy from vibration and that it displayed self-powering and self-sensing capabilities.

The primary objective of this paper is to evaluate the developed energy harvesting MR damper-based vibration reduction system implemented in a single DOF mechanical structure and to demonstrate its feasibility. This paper is organised as follows. Section 2 summarises the design structure and characteristics of the energy harvesting MR damper. Section 3 briefly describes the vibration reduction system based on an energy-harvesting MR damper whilst Section 4 deals with its implementation in a single DOF mechanical system. Section 5 summarises the experimental testing of the proposed system under conditions when the MR damper is not energised, while it was energised from an external power source and when it is energised using harvested energy. Final conclusions are given in Section 5.

\section{Energy harvesting MR damper}

The system comprising an MR damper and a power generator integrated into a single device is shown in Fig. 1. The power generator is connected to the MR damper via piston rod (1) and placed inside housing (2). Three systems of permanent magnets (3) in the generator are fixed on the rod separated by ferromagnetic spacers. In each system, the magnets are arranged in

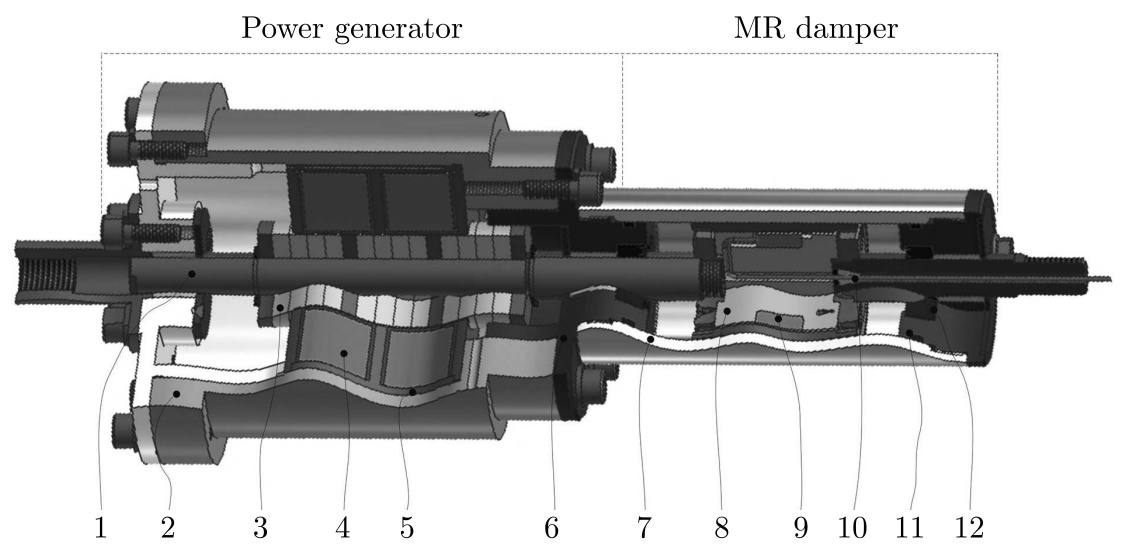

Fig. 1. Energy harvesting MR damper: 1-shaft, 2-generator housing, 3-magnets, 4-coil housing, 5 -generator coil, 6-switch cover, 7 -cylinder, 8-piston, 9-control coil, 10-wire, 11-cover, 12 -seal 
(a)

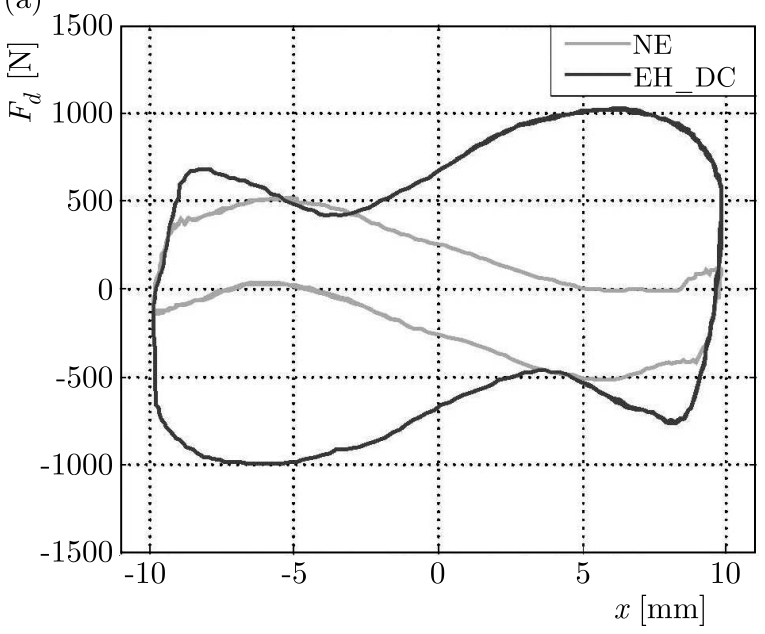

(b)

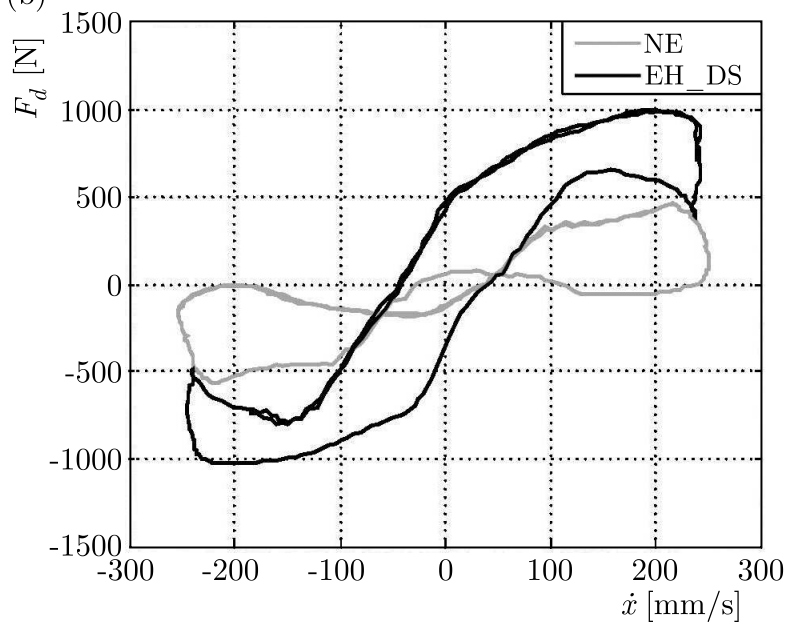

Fig. 2. Force vs.: (a) piston displacement, (b) piston velocity

accordance with their axial polarity whilst the systems of magnets have opposite polarisation with respect to each other. The rod with the magnet systems moves inside generator coil (4) placed inside ferromagnetic casing (5). The generator is separated from the damper by cover (6) to which cylinder (7) is fixed. Inside the cylinder, piston (8) is placed. On its both ends there are two rod sections attached: the solid section - from the generator end, the section with an opening - on the opposite end. Inside the piston there is control coil (9), and power supply cable (10) is led through the opening in the rod. The cylinder is closed with cover (11) and filled with MR fluid. Covers (6) and (11) are provided with pilot sleeves and sealing rings (12). The damper force vs piston displacement / piston velocity plots obtained for the applied kinematic input (sine excitation with amplitude $A=10 \mathrm{~mm}$ and frequency $f=4 \mathrm{~Hz}$ ) are shown in Figs. 2a and $2 \mathrm{~b}$. The plots graphed with the continuous line represent the case when the generator coil is not connected to the damper coil - the damper is not energised (NE case), and those graphed with broken lines represent the case when the damper is energised using the harvested energy and the damper coil is directly connected to the MR damper coil (EH_DS case). Obviously, a larger force will be registered in EH_DS. case than in NE case.

\section{Vibration reduction system}

The structural design of the vibration reduction system is shown in Fig. 3. It comprises a spring (with stiffness coefficient $126.4 \mathrm{~N} / \mathrm{mm}$ ) and the energy harvesting MR damper connected in

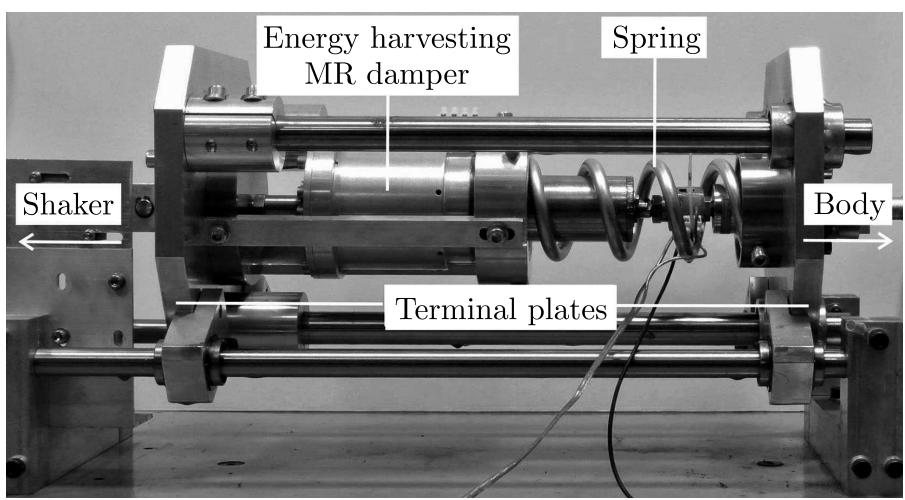

Fig. 3. Structure of the vibration reduction system 
parallel. The damper and the spring are fixed between two terminal plates and connected on one end to a shaker and on the other end - to a mobile body mass comprising three horizontally arranged plates (with mass $153 \mathrm{~kg}$ ). Trolleys moving along linear guides enable its movement along the horizontal axis. The energy harvesting MR damper is mounted in the vibration reduction system, on the shaker end, with a fixing grip and from the body mass end, via threaded connection in the rod.

\section{Evaluation tests}

\subsection{Test facility}

The test facility shown schematically in Fig. 4 incorporates a shaker, an energy harvesting MR damper, a spring and a body, two displacement sensors (Sensor 1, Sensor 2), force sensor (Sensor 3) and the measurement - control system comprising a PC computer with the AD/DA card supported by Windows and using the MATLAB/Simulink software. Recorded parameters include the shaker core displacement (excitation signal) $-z$, body displacement $-x$, damper force $F_{d}$, voltage in the damper coil /electromotive force (emf) produced in the generator coil $-u / e$, current $i$ in the damper coil and voltage controlling the transistor switch (not shown) $u_{c}$. The measured quantities are converted into voltage signals in the range $(-10,+10) \mathrm{V}$ and sampled with a frequency of $1 \mathrm{kHz}$.

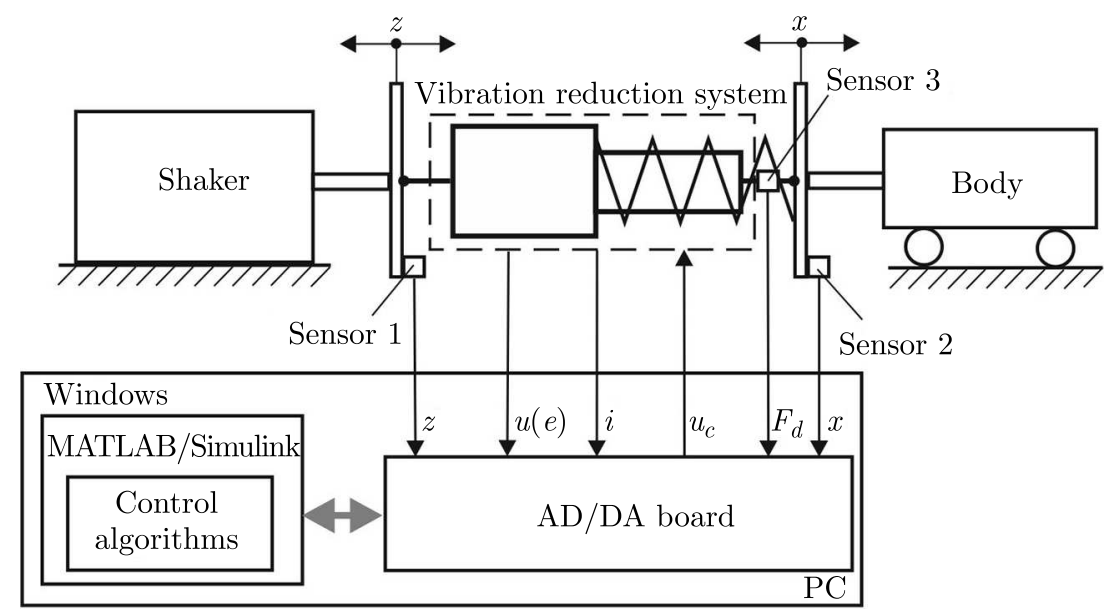

Measurement and control system

Fig. 4. Schematic diagram of the test facility

\subsection{Results}

The system is investigated under conditions when the MR damper is not energised (NE case) and when it is energised from the power generator (EH case). In the $\mathrm{EH}$ case, the damper is powered either directly with voltage produced by the generator (EH_DS case) or by using the control system with an on-off algorithm (EH_OO case) or a sky-hook algorithm (EH_SK case). Tests are performed under the applied sine excitations $z$ with amplitude $A=4.5 \mathrm{~mm}$ and frequency $f$ in the range $(1,10) \mathrm{Hz}$. In further Sections, we show time patterns of registered quantities obtained for $f=4 \mathrm{~Hz}$, which corresponds to the near-resonance frequency of the investigated system implemented in a single DOF mechanical structure. 
NE case

Figure 5 shows time histories of emf generated in the generator coil and of the damper force. In this case, the damper force has the following components: force due to drag experienced during the fluid flow in the piston slit, friction force in the sealing elements and the cogging force in the generator. The maximal value of emf is found to be $10 \mathrm{~V}$, and the maximal damper force becomes $F_{d}=520 \mathrm{~N}$. In earlier work, it was demonstrated that emf was linearly related to piston velocity (Sapiński, 2014).

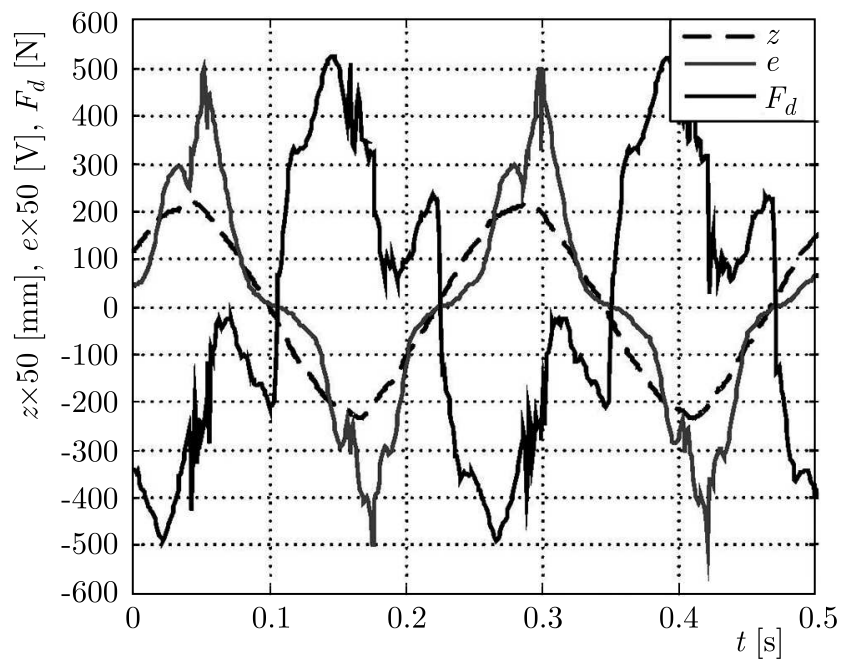

Fig. 5. Emf and force vs time

EH case

The equivalent electric circuit of the damper in the EH case is shown in Fig. 6. There is a Graetz bridge between the generator coil and the damper coil. $R_{g}$ and $L_{g}$ stand for the resistance and induction of the generator coil and $R_{d}$ and $L_{d}$ - resistance and induction of the damper coil. Plots of voltage vs. time and current vs. time in this circuit and the generated damper force are given in Fig. 7.

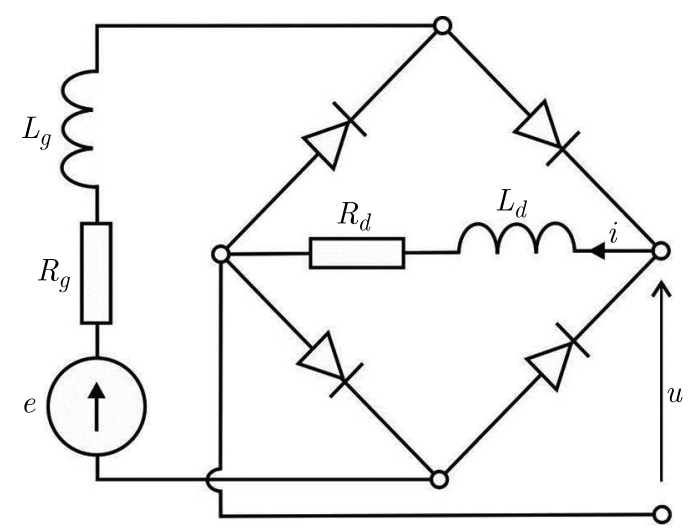

Fig. 6. Equivalent electric circuit of the energy harvesting MR damper with a Graetz bridge

The maximum voltage and current level in the damper coil is $2 \mathrm{~V}$ and $0.2 \mathrm{~A}$. The plot of force reveals the presence of a force component related to the current in the damper force (unlike NE case). It appears that the maximal force value is reduced from 520 to $450 \mathrm{~N}$, which is caused by the presence of the cogging force in the generator, arising in the permanent magnet-ferromagnetic 


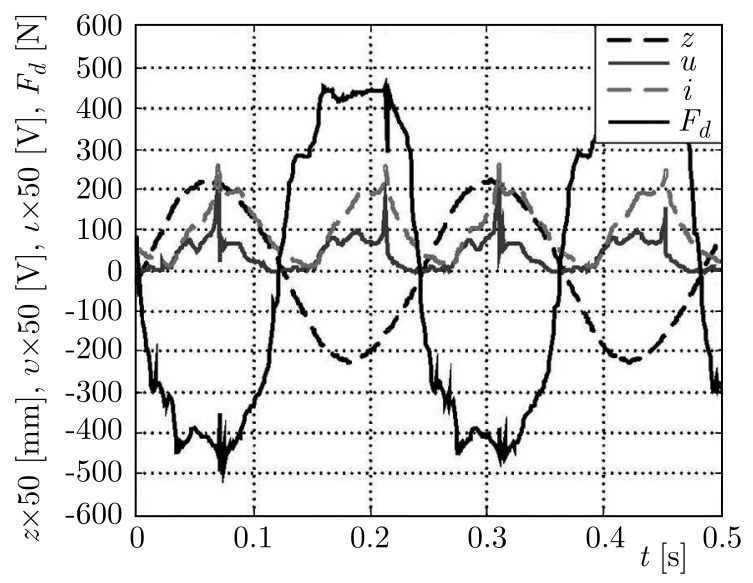

Fig. 7. Voltage, current and force vs. time

element systems (Sapinski, 2014), and the amplitude of piston displacement becomes $10 \mathrm{~mm}$ in the NE case and $2.5 \mathrm{~mm}$ in the EH_DS case. Plots of the force FMR generated by the MR damper (Fig. 1) vs time for those two cases are compared in Fig. 8. It appears that the maximum force value tends to increase with the an increase in the coil current and becomes $325 \mathrm{~N}$ in the NE case and $520 \mathrm{~N}$ in the EH_DS case.

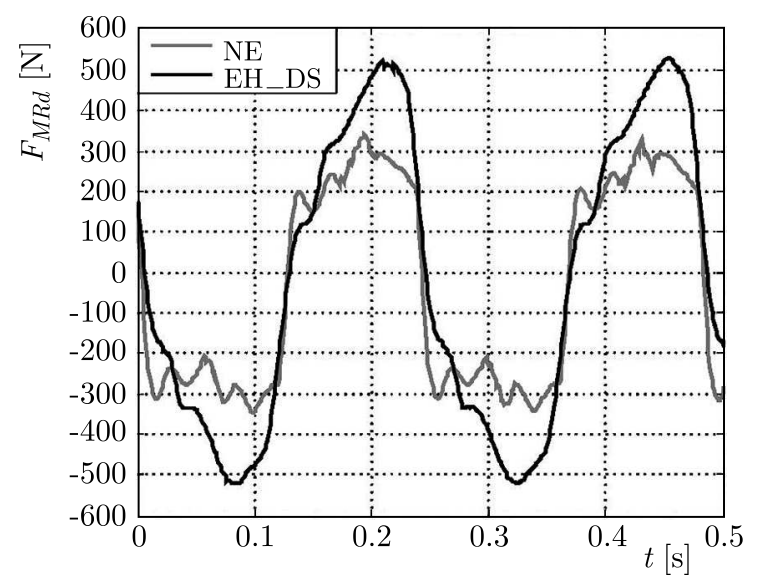

Fig. 8. MR damper force vs. time

Control of the current level in the damper coil is effected using the on-off and sky-hook control algorithms (Braun, 2002), utilising the information about velocity of the body $\dot{x}$ and its relative velocity $(\dot{x}-\dot{z})$ based on the measured displacements $x$ and $z$. The controllers performance is largely dependent on the quality of signals $\dot{x}$ and $\dot{z}$. Because MR dampers are capable only of dissipating energy, on-off and sky-hook algorithms had to be modified such that the current level in the coil should be minimal in those time instants when energy should be supplied to the system. Figures $9 \mathrm{a}$ and $9 \mathrm{~b}$ show a schematic diagram of the system for controlling coil current using the EH_OO and EH_SK algorithms. The current level in the damper coil depends on whether the damper coil is connected to the generator coil or disconnected, which is effected using a transistor switch $\mathrm{K}$. The transistor switch $\mathrm{K}$ remains on as long as the voltage across its controls $u_{c}$ should be $0 \mathrm{~V}$. When voltage becomes $3.3 \mathrm{~V}$, the transistor switch is off. A diode $D_{0}$ is provided to release the energy accumulated in the damper coil (when the transistor switch $\mathrm{K}$ is off). 
(a)

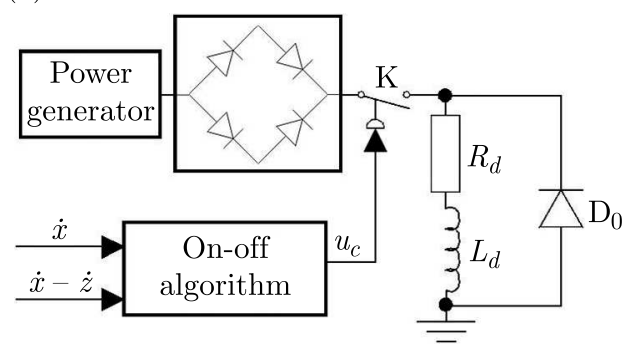

(b)

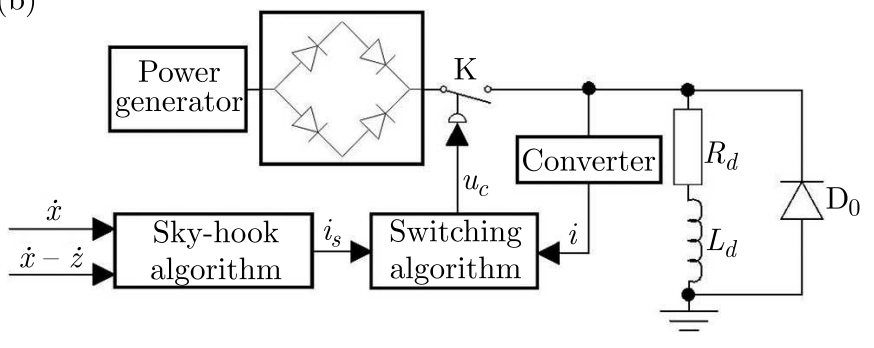

Fig. 9. Schematic diagram of the control system: (a) EH_OO case, (b) EH_SK case

The damper force generated in accordance with the on-off algorithm is expressed by (4.1) ${ }_{1}$. To ensure the required force value, the current level in the damper coil should be governed by formula $(4.1)_{2}$

$$
F_{d}=\left\{\begin{array}{ll}
F_{\max } & \dot{x}(\dot{x}-\dot{z}) \geqslant 0 \\
0 & \dot{x}(\dot{x}-\dot{z})<0
\end{array} \quad i= \begin{cases}i_{\max } & \dot{x}(\dot{x}-\dot{z}) \geqslant 0 \\
0 & \dot{x}(\dot{x}-\dot{z})<0\end{cases}\right.
$$

The operating principle of the vibration reduction system in the EH_OO case is illustrated by the plots of key parameters in function of time, shown in Figs. 10 and 11. When the energy in the system is to be dissipated $(\dot{x}(\dot{x}-\dot{z}) \geqslant 0)$, the damper should deliver the maximum force, $F_{d}=F_{\max }$. In order to achieve this, the transistor switch should be closed, producing the current flow $i=i_{\text {max }}$ in the damper coil. When energy is to be supplied $(\dot{x}(\dot{x}-\dot{z})<0)$, the transistor switch $\mathrm{K}$ should be open $\left(i=0, F_{d}=0\right)$.

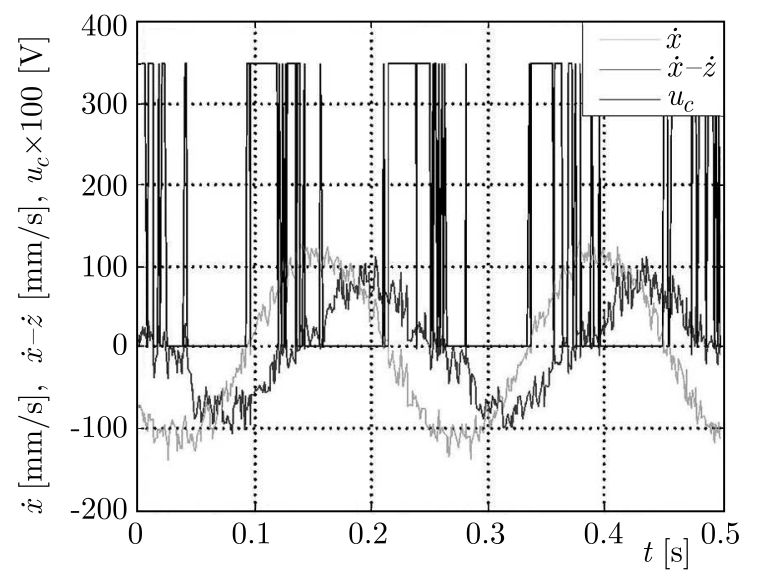

Fig. 10. Absolute velocity, relative velocity and control vs. time

However, the force $F_{d} \neq 0$, because of the contribution of the damper force components independent of the current level.

Frequent switching of the transistor switch $\mathrm{K}$ at instants when the signals and $\dot{x}$ and $(\dot{x}-\dot{z})$ become zero is caused by signal disturbances. This effect has only slight influence on the current level in the damper coil, which can be also observed in the EH_SK case.

The damper force generated in accordance with the sky-hook algorithm is expressed by $(4.2)_{1}$. To ensure the required force value, the current level in the damper coil should be given by formula $(4.2)_{2}$ 


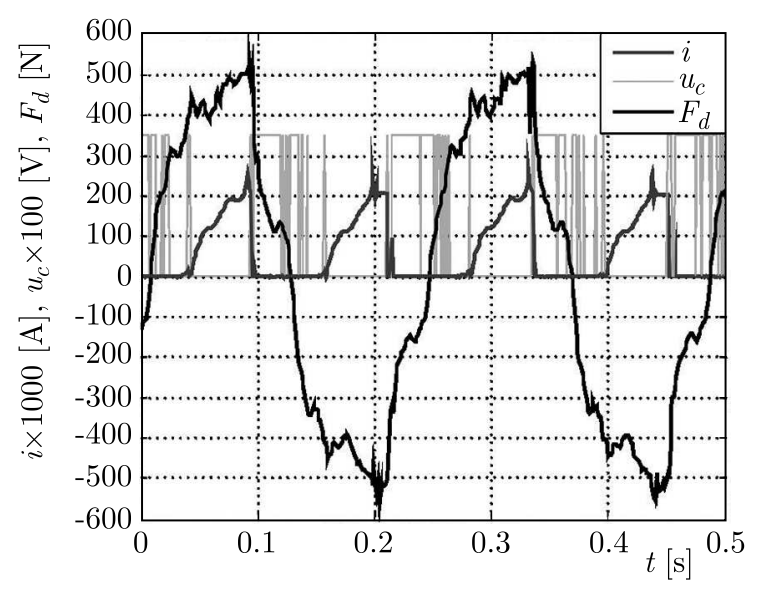

Fig. 11. Current level, control and force vs. time

$$
F_{d}=\left\{\begin{array}{ll}
-c \dot{x} & \dot{x}(\dot{x}-\dot{z}) \geqslant 0 \\
0 & \dot{x}(\dot{x}-\dot{z})<0
\end{array} \quad i_{s}= \begin{cases}b|\dot{x}| & \dot{x}(\dot{x}-\dot{z}) \geqslant 0 \\
0 & \dot{x}(\dot{x}-\dot{z})<0\end{cases}\right.
$$

where $c$ is the damping coefficient, $b$ - proportionality factor.

The value of the proportionality factor $b=0.0015 \mathrm{~A} \cdot \mathrm{s} / \mathrm{mm}$ has been chosen experymentally. The operating principle of the vibration reduction system in the EH_OO case is demonstrated by the plots of key parameters in function of time, shown in Figs. 12-14. The transistor switch K is switched by comparing the current level $i$ (measured with a current-voltage converter and standard resistance) and the predicted value $i_{s}$, derived from the algorithm. The transistor switch $\mathrm{K}$ is closed $\left(u_{c}=0\right)$ when $i_{s} \geqslant i$.

(a)

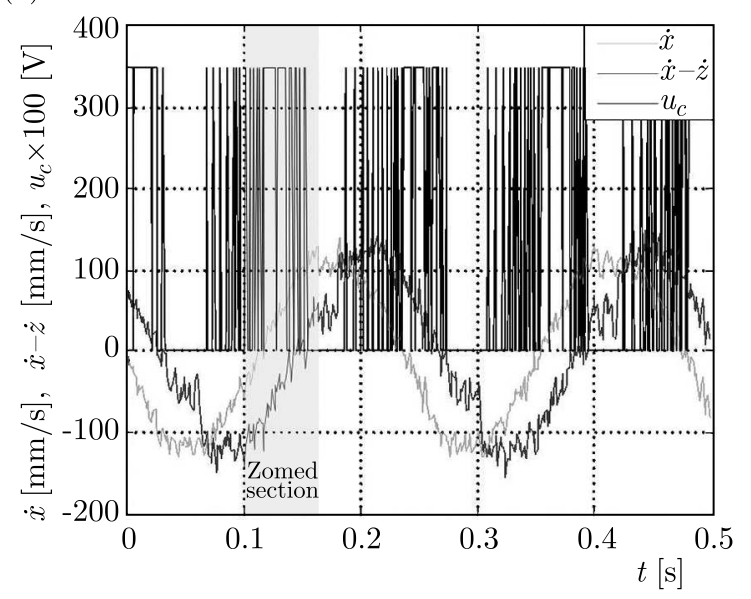

(b)

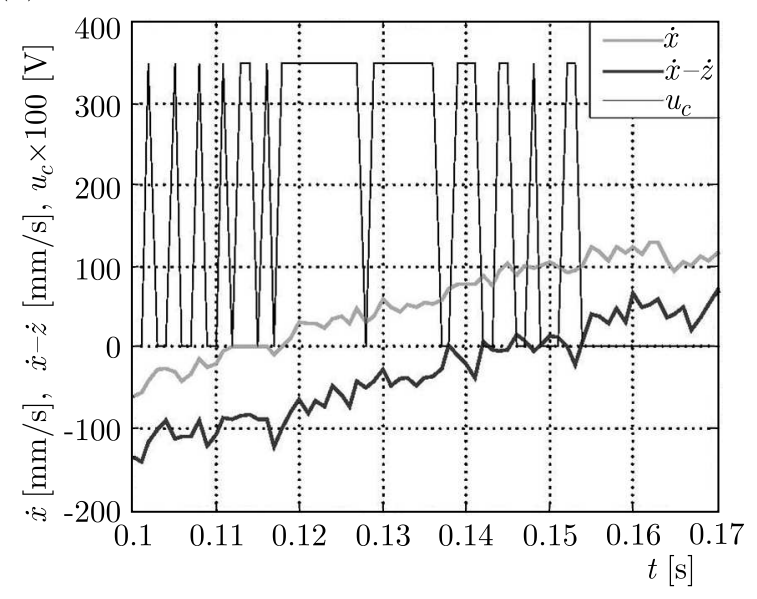

Fig. 12. Absolute velocity, relative velocity and control vs: (a) time, (b) time (zoomed section)

Frequent switching of the transistor switch $\mathrm{K}$ is caused not only by velocity signal disturbances (Fig. 12) as in the EH_OO case, but also by the current level exceeding $i_{s}$ (Fig. 13). At the instant the damper coil is disconnected from the generator coil, the energy accumulated in the damper coil is discharged by the diode $D_{0}$ in a very short time, leading to rapid reduction of the current level $i$. The sampling frequency directly affects the current level stability with respect to the present value. An increase in the current during the subsequent switching of the transistor switch is associated with the damper coil inertia and the instantaneous voltage produced by the generator. Plots of the force $F_{d}$ and current $i$ in the EH_SK case in function of time are shown in Fig. 14. 


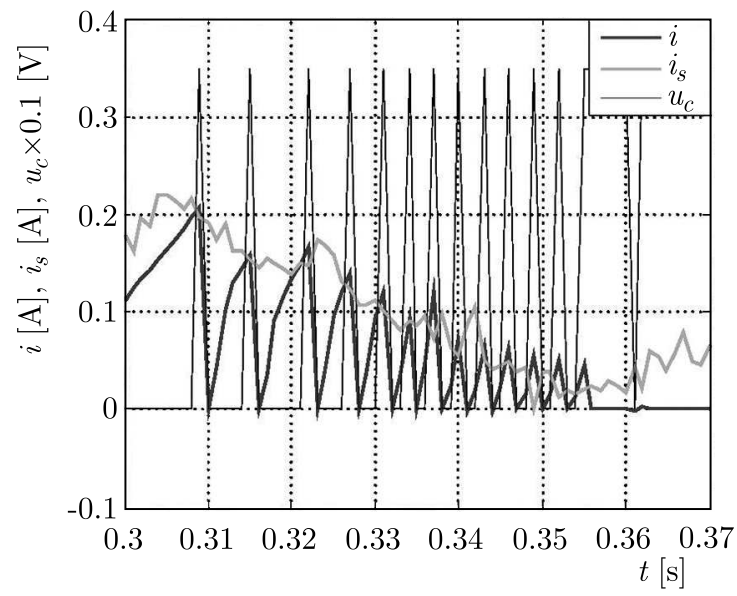

Fig. 13. Current and control vs. time

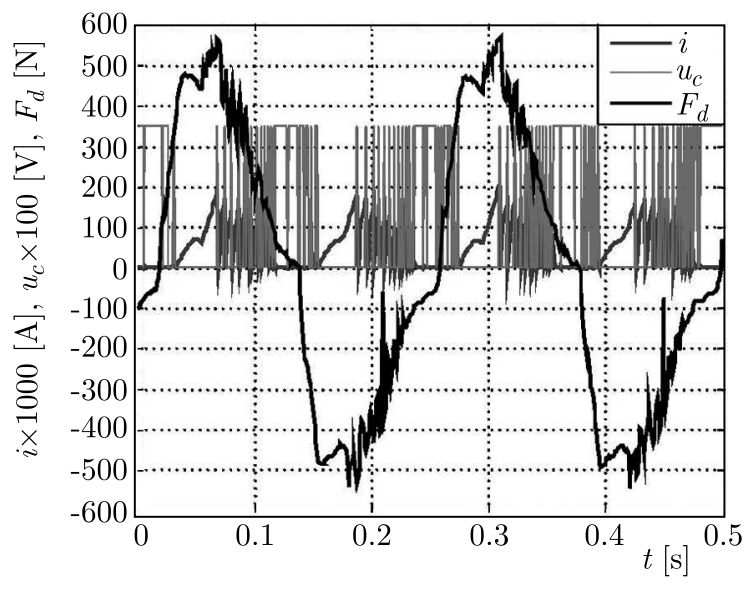

Fig. 14. Current level, control and force vs. time

The dependence of rms value of the damper force on frequency in each investigated case is given in Fig. 15, showing an increase in the rms value of the force $F_{d}$ with an increase in the current level $i$. The efficiency of the investigated vibration reduction system is evaluated basing on the transmissibility coefficient $\left(T_{x z}\right)$ expressed by the formula

$$
T_{x z}=\frac{\sqrt{\frac{1}{T} \int_{t}^{t+T} x(t)^{2} d t}}{\sqrt{\frac{1}{T} \int_{t}^{t+T} z(t)^{2} d t}}
$$

where $T$ is the period of the signal.

The values of $T_{x z}(f)$ obtained in all analysed cases and in the predetermined frequency range are compared in Fig. 16. It appears that the system performance is the best in the EH_SK configuration. In this case, the value of $T_{x z}$ for near-resonance frequencies approaches 1.17, for other frequencies it is near to that obtained in the NE case. Even though $T_{x z}$ values for near-resonance frequencies are slightly lower in the EH_OO and EH_DS case (1.11 and 1.12), one has to bear in mind that at higher frequencies, $T_{x z}$ tends to increase, which results in deterioration of the system performance. 


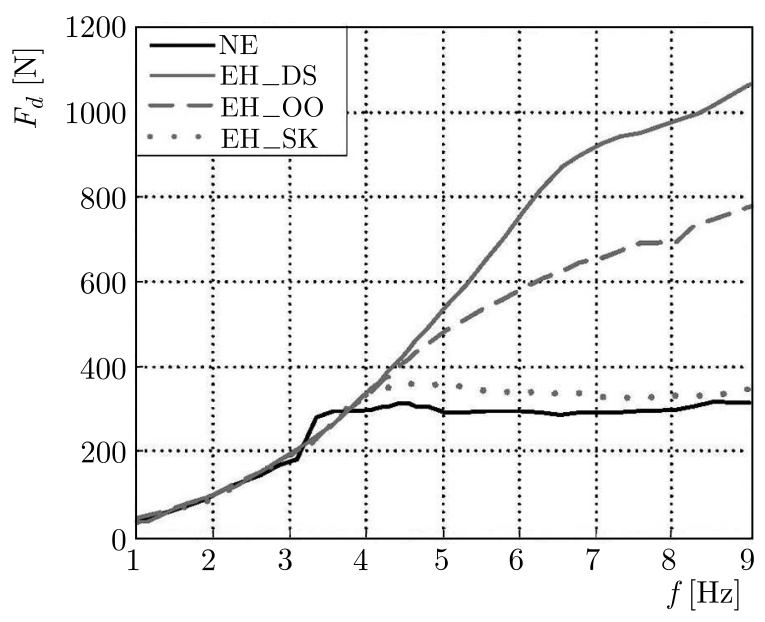

Fig. 15. rms force vs. frequency

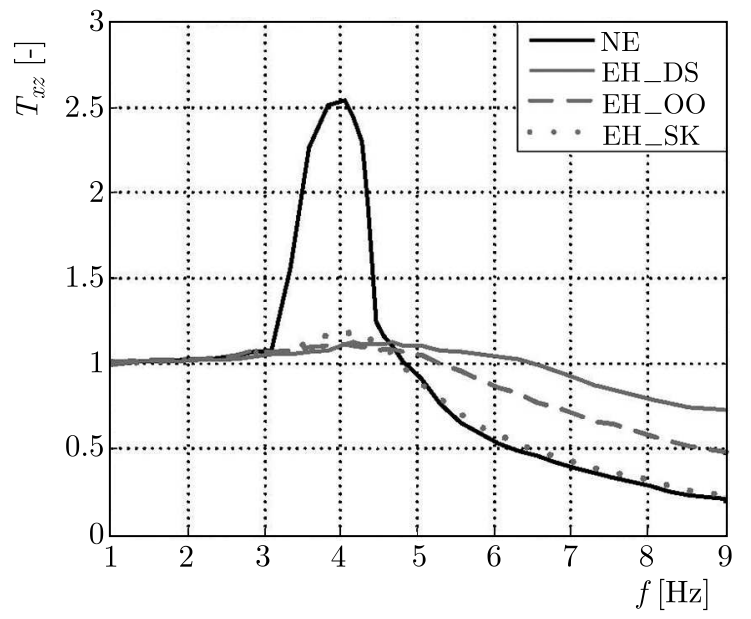

Fig. 16. Transmissibility vs. frequency

\section{Conclusions}

This study summarises experimental investigations of a MR damper based vibration reduction system with energy harvesting capability employed in a single DOF mechanical structure. The main purpose is to evaluate the performance of the engineered vibration reduction system and to demonstrate its feasibility.

The system is investigated in four modes of its operation: when the damper is not energised (NE case), when the damper is energised and directly power-supplied with voltage produced by the generator (EH_DS case), when the control system with an on-off algorithm is used (EH_OO case) and when the sky-hook control algorithm is applied (EH_SK case). The experimental results lead us to the following conclusions:

- the vibration reduction system supplied with harvested energy features a decidedly lower transmissibility coefficient $T_{x z}$ at near-resonance frequencies;

- despite a slight increase of $T_{x z}$ in the frequency range $(3,4.5) \mathrm{Hz}$, the vibration reduction system performs best in the EH_SK case;

- the system performance in the EH_OO and EH_SK case is largely affected by the quality of signals $\dot{x}$ and $(\dot{x}-\dot{z})$, obtained after processing of the measured displacement signals $x$ and $z$; 
The research has been now undertaken to find out how to manage the harvested energy such that it could be effectively utilised to power-supply the components of the vibration reduction system (MR damper, sensors, control system).

Acknowledgemment

This work has been supported by AGH University of Science and Technology under research program No. 11.11.130.958.

\section{References}

1. Braun S., Ewins D., Rao S.S., 2002, Encyclopedia of vibration, Academic Press, 1 (Active Control of Vehicle Vibration: Ahmadian M.), 37-45

2. Chen C., Liao W.H., 2012, A self-sensing magnetorheological damper with power generation, Smart Materials and Structures, 21, 02501

3. Cho S.W., Jung H.J., LeE I.W., 2005, Smart passive system based on a magnetorheological dampers, Smart Materials and Structures, 1, 707-714

4. Cho S.W., Park K.S., Kim Ch.H., Lee I.W., 2004, Smart passive system based on MR damper, $1^{\text {st }}$ International Conference "From Scientific Computing to Computational Engineering"

5. Choi K.M., Jung H.J., Lee I.W., Cho S.W., 2007, Feasibility study of an MR damper-based smart passive control system employing an electromagnetic induction device, Smart materials and Structures, 16, 2323-9

6. Choi Y.T., Werely N.M., 2009, Self-powered magnetorheological dampers, Journal of Vibration Acoustics, 131, 44-50

7. Hong J.H., Choi K.M., Lee J.H., OH J.W., Lee I.W., 2007, Experimental study on smart passive system based on MR damper, Proceedings of the 18th KKCNN Symposium on Civil Engineering, Taiwan

8. Jung H.J., Jang D.D., Cho S.W., Koo J.H., 2009, Experimental verification of sensing capability of an electromagnetic induction system for an MR fluid damper based control system, 11th Conference on Electrorheological Fluids and Magnetorheological Suspensions, Journal of Physics: Conference Series, 149

9. Jung H.J., Jang D.D., Koo J.H., Cho S.W., 2010, Experimental evaluation of a self-sensing capability of an electromagnetic induction system designed for MR dampers, Journal of Intelligent Material Systems and Structures, 21, 837-836

10. Lam K.H., Chen Z.H., Ni Y.Q., Chan H.L.W., 2010, A magnetorheological damper capable of force and displacement sensing, Sensors and Actuators A: Physical, 158, 1, 51-59

11. Li Z., Zhuo L., KuAng J., Luhrs G., 2013a, Energy-harvesting shock absorber with a mechanical motion rectifier, Smart Materials and Structures, 22, 028008

12. Li Z., Zhuo L., Luhrs G., Lin L., Qin Y., 2013b, Electromagnetic energy-earvesting shock absorbers: design, Modeling and Road Tests, IEEE Transactions on Vehicular Technology, 62, 3, $1065-1074$

13. SAPIŃsKi B., 2011, Experimental study of a self-powered and sensing MR damper-based vibration control system, Smart Materials and Structures, 20, 105007

14. SAPIŃski B., 2014, Energy harvesting MR linear damper: prototyping and testing, Smart Materials and Structures, 23, 035021

15. Snamina J., SApiński B., 2011, Energy balance in self-powered MR damper-based vibration reduction system, Bulletin of the Polish Academy of Sciences Technical Sciences, 59, 1, 75-80 
16. WANG D.H., BAI X.X., 2013, A magnetorheological damper with an integrated self-powered displacement sensor, Smart Materials and Structures, 22, 075001

17. Wang D.H., Bai X.X., Liao W.H., 2010, An integrated relative displacement self-sensing magnetorheological damper: prototyping and testing, Smart Materials and Structures, 19, 105008

18. Zhu S.Y., Shen W.A., Xu Y.L., Lee W.C., 2012, Linear electromagnetic devices for vibration damping and energy harvesting: Modeling and testing, Engineering Structures, 34, 198-212

Manuscript received June 16, 2015; accepted for print July 28, 2015 